\title{
EFFECT OF AORTIC INSUFFICIENCY ON ARTERIAL BLOOD PRESSURE, CORONARY BLOOD FLOW AND CARDIAC OXYGEN CONSUMPTION ${ }^{1}$
}

\author{
BY RENÉ WÉGRIA, GERHARD MUELHEIMS, ${ }^{2}$ JAMES R. GOLUB, ${ }^{3}$ ROBERT \\ JREISSATY, AND JIRO NAKANO 4
}

(From the Department of Medicine, Columbia University College of Physicians and Surgeons, and the Presbyterian Hospital, New York, N. Y.)

(Submitted for publication September 19, 1957; accepted November 21, 1957)

In patients with aortic insufficiency and without disease of the coronary ostia or arteries, the occurrence of chest pain having some or many of the characteristics of cardiac pain due to myocardial ischemia has been ascribed classically to a decrease in the coronary blood flow $(1,2)$, the aortic insufficiency presumably decreasing the coronary blood flow by lowering the mean aortic diastolic pressure. However, the data available on the effect of aortic insufficiency on the coronary blood flow are contradictory. From acute experiments on the anesthestized dog, Green (3), as well as Green and Gregg (4), concluded that when the aortic insufficiency is marked enough to lower the aortic diastolic pressure, the increase in coronary blood flow occurring during systole does not compensate for the decrease in flow during diastole and the mean coronary flow decreases. On the other hand, Foltz, Wendel, and West (5), from measurements made on anesthetized dogs in which one or two aortic cusps had been torn three or more days previously, concluded that the coronary blood flow was increased over levels usually observed in normal dogs while oxygen consumption was greatly increased over normal levels. Because of the discrepancy in the opinions about the effect of aortic insufficiency on the coronary blood flow, it was thought advisable to reinvestigate this problem.

\section{METHODS}

Eight dogs weighing between 17 and 40 kilograms were anesthetized by the intravenous administration of

${ }^{1}$ This work was made possible by grants-in-aid from the New York Heart Association, the Sidney A. Legendre Gift and the Charles A. Frueauff Gift.

2 Postdoctorate Fellow of the United States Public Health Service.

${ }^{3}$ Fellow of the Dazian Foundation for Medical Research.

4 Research Fellow of the Hudson County (N. J.) Heart Association.
$10 \mathrm{ml}$. per kilogram of weight of a 1 per cent chloralose solution. In the first four dogs the trachea, both common carotid arteries and both external jugular veins were exposed through a midline incision and a $\mathrm{Y}$-shaped glass tube inserted into the trachea. Under artificial respiration, the left hemithorax was opened, the pericardium incised and the heart suspended in a pericardial cradle. The method used to measure and continuously record the output of the left ventricle was a modification of that previously described in this laboratory (6). The proximal ends of the left subclavian artery and brachiocephalic trunk were cannulated. Then the aorta was clamped distally to the subclavian artery so that the blood ejected by the left ventricle was directed into an electromagnetic rotameter (7) and returned to the circulation via both carotid arteries cannulated distally as well as both femoral arteries cannulated proximally and distally. Since the coronary sinus drains blood essentially only from the left coronary artery $(8,9)$ and since, in a given animal, the coronary sinus blood flow represents a constant portion of the left coronary artery flow (8), measurement of the coronary sinus blood flow was used as a means of studying the left coronary artery blood flow. For that purpose, a cannula was introduced via the left external jugular vein into the coronary sinus and tied in place by a string passed around the coronary sinus. All the blood emerging from the coronary sinus through this cannula was directed into a second rotameter by means of which the coronary sinus blood flow was measured and continuously recorded. The coronary sinus blood was returned to the dog through a cannula introduced via the right external jugular vein down to the junction of the right auricle and the superior vena cava. Mean arterial blood pressure was recorded from the root of the aorta with a dampened Gregg manometer. Left ventricular output, mean aortic blood pressure and coronary sinus blood flow were continuously recorded on photographic paper. The heart rate was obtained by direct timing, from the blood pressure tracing or from an electrocardiographic tracing. In the other four dogs the output of the left ventricle was not measured and the coronary sinus flow was measured as in the first four dogs. The mean femoral arterial blood pressure was recorded with a dampened Gregg manometer and the aortic pressure curve was recorded from the root of the aorta with another optical manometer. The instrument used to produce acute aortic insufficiency was the um- 
TABLE I

Effect of aortic insufficiency on heart rate, arterial blood pressure, cardiac output, coronary blood flow, coronary blood arteriovenous oxygen difference and cardiac oxygen consumption

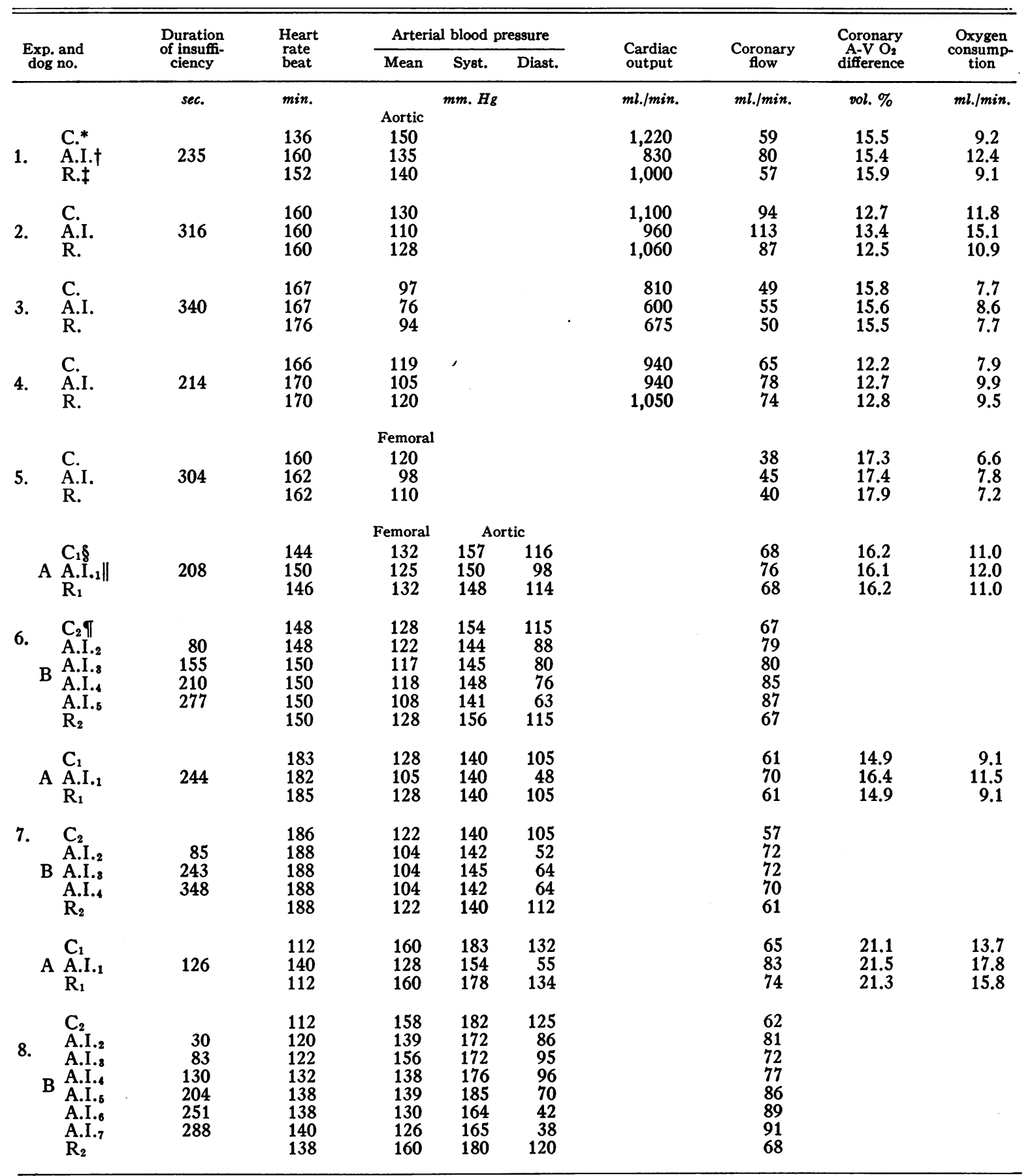

* C., control.

$\dagger$ A.I., aortic insufficiency.

R., recovery.

\& $\mathrm{C}_{1}$, control for part $\mathrm{A}$

A.I.1,2, etc., aortic insufficiency of severity increasing or decreasing stepwise.

of $C_{2}$, control for part $B$. 
brella type valve spreader previously described by Wiggers and Maltby (10). While blood pressure, coronary sinus blood flow and in some experiments left ventricular output were being continuously recorded, the valve spreader was slipped into the aortic ring through the left ventricular wall. The introduction of the instrument into the aortic ring was without effect on blood pressure, left ventricular output and coronary sinus flow. Proper positioning of the instrument was judged by palpation and the correctness of the position of the instrument was checked by direct visualization at the end of each experiment.

In all eight experiments, after a control period an aortic insufficiency severe enough to lower definitely the mean and/or diastolic arterial blood pressure was induced and maintained from 126 to 340 seconds, after which a period of recovery was observed. Arterial and coronary sinus blood samples were drawn simultaneously at the end of the control period, the period of aortic insufficiency and during the recovery period. The oxygen content of the arterial and venous bloods was determined in duplicate by the method of Van Slyke and Neill (11). The oxygen consumption of that portion of the myocardium drained by the coronary sinus was calculated according to the following formula:

Oxygen consumption (expressed in $\mathrm{ml}$. per minute) equals coronary sinus blood flow (expressed in $\mathrm{ml}$. per minute) times coronary oxygen arteriovenous difference (expressed in ml. per cent) times $10^{-2}$.

In three of the eight experiments, after the completion of that part of the experiment in which the effect of aortic insufficiency on oxygen consumption of the myocardium, arterial blood pressure and coronary blood flow was studied, an attempt was made to induce aortic insufficiency, then to increase (or decrease) the severity of the aortic insufficiency stepwise in order to establish the effect of aortic insufficiency of progressively increasing (or decreasing) severity on arterial blood pressure and coronary blood flow.

\section{RESULTS AND DISCUSSION}

The results observed are summarized in Table I and Figure 1. The effect of aortic insufficiency on coronary blood flow and cardiac oxygen consumption was studied in eight experiments on eight dogs. In all eight experiments, aortic insufficiency lowered the mean arterial blood pressure, the decrease ranging from 7 to $32 \mathrm{~mm}$. of mercury, and despite the sudden drop in mean arterial pressure the coronary flow rose in all eight experiments, the increase amounting from 12 to 36 per cent. The oxygen consumption rose in all eight experiments and this rise amounted from 9 to 35 per cent. In three experiments, this increase in oxygen consumption was due to the increase in coronary flow alone, the coronary blood oxygen ar-

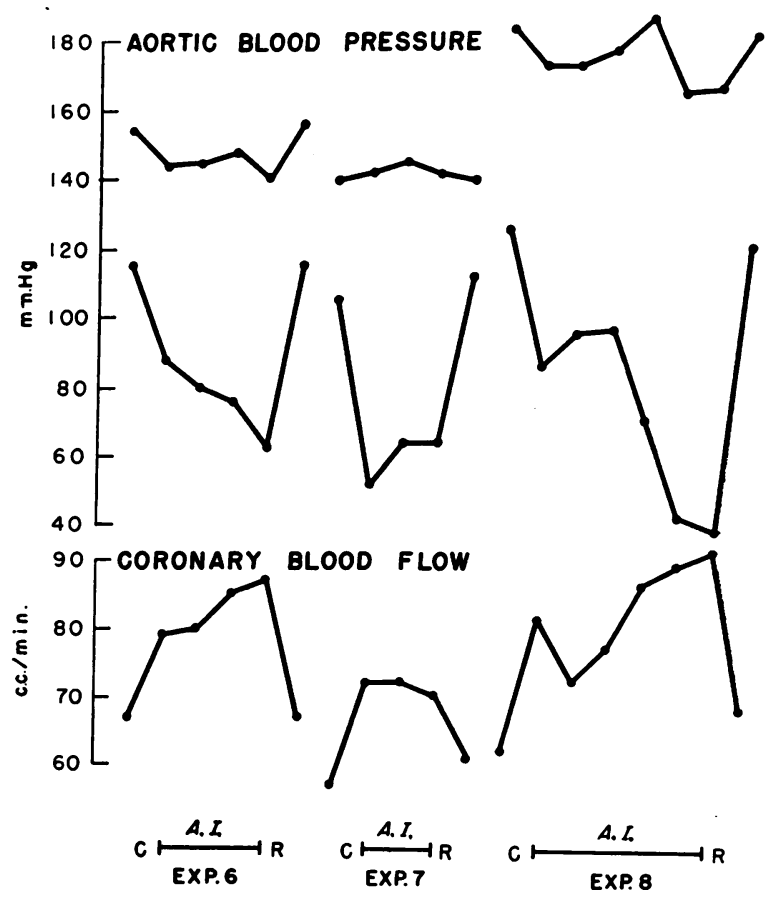

Fig. 1. Plot of Part B of Experiments 6, 7 and 8, Illustrating the Effect of Acute Aortic InsuffiCIENCy OF Severity Increasing (OR Decreasing) STEPWISE

Upper tracings, systolic and diastolic aortic blood pressure; scale in $\mathrm{mm}$. of mercury. Lower tracing, coronary sinus blood flow; scale in $\mathrm{ml}$. per minute.

C, control; A.I., aortic insufficiency of severity increasing (or decreasing) stepwise; $R$, recovery.

teriovenous difference remaining unchanged. In the other five experiments, most of the increase in oxygen consumption was contributed by the increase in coronary flow, although the coronary blood oxygen arteriovenous difference increased somewhat. The output of the left ventricle, i.e., the effective cardiac output, was decreased in three of the four experiments in which it was measured and unchanged in one experiment. The heart rate was not at all or only slightly affected by the aortic insufficiency, except in two experiments in which it rose significantly. These latter two experiments were otherwise similar to the rest of the experiments. In Part A of Experiments 6, 7 and 8 , in which the aortic pressure curve as well as the mean arterial femoral pressure was recorded, the mean arterial blood pressure was observed to fall from 132,128 and $160 \mathrm{~mm}$. of mercury to 125,105 and $128 \mathrm{~mm}$. of mercury, re- 
spectively, and the diastolic pressure in the same experiments fell from 116, 105 and 132 to 98,48 and $55 \mathrm{~mm}$. of mercury, respectively. In Part B of Experiments 6, 7 and 8, illustrated in Figure 1 , the stepwise increase in the severity of the aortic insufficiency resulted in a stepwise decrease in the mean arterial blood pressure as well as aortic diastolic pressure, and in a stepwise increase in the coronary flow. Part B of these three experiments shows that although the mean arterial blood pressure fell from 128, 122 and 158 $\mathrm{mm}$. of mercury to minima of 108, 104 and 126 $\mathrm{mm}$. of mercury, respectively, and although the diastolic pressure fell from 115, 105 and 125 to minima of 63,52 and $38 \mathrm{~mm}$. of mercury, respectively, the coronary flow rose stepwise to values 28, 15 and 47 per cent above control level, respectively. From these data there seems to be little doubt that acute aortic insufficiency increases the cardiac oxygen consumption and the coronary blood flow, even when the aortic insufficiency is severe enough to produce a marked decrease in mean arterial blood pressure and aortic diastolic pressure. As a matter of fact, within the limits of the present experiments, the more severe the aortic insufficiency was and the lower the mean arterial and aortic diastolic pressure fell, the more the coronary blood flow increased, as demonstrated by the second part of Experiments 6, 7 and 8 .

These results are in disagreement with those of Green (3) and Green and Gregg (4), who, in acute experiments on anesthetized dogs, found that aortic insufficiency always decreased the coronary blood flow. Because partial occlusion of the aorta during aortic insufficiency could raise the coronary blood flow to or above control level by raising the mean aortic pressure, these authors postulated the possibility that, if aortic insufficiency induced sufficient peripheral vasoconstriction to restore the mean arterial pressure to its control level, aortic insufficiency could raise the coronary blood flow. However, they never actually observed such an occurrence, and in their experiments aortic insufficiency alone always lowered the coronary flow. It must be pointed out that the control arterial blood pressure of their animals was quite low and a decrease in the head of pressure at those very low levels of aortic pressure may have more of an effect on the coronary flow than the same decrease in the head of pressure at higher levels of aortic pressure. However, this would hardly seem to be the only factor responsible for the discrepancy between Green and Gregg's observations and the present study. Indeed, it should be kept in mind that the condition of dogs with as low a control arterial blood pressure as reported in the observations published by Green and Gregg is such that these dogs most probably respond to the induction of aortic insufficiency differently from dogs with a higher and more normal control arterial blood pressure as well as cardiovascular system in general. On the other hand, Foltz, Wendel, and West (5) observed that during aortic insufficiency "coronary blood flow was increased over levels usually observed in normal dogs, while oxygen consumption was greatly increased over normal values." Unfortunately, no control values for the blood pressure were given by these authors and it was therefore difficult to estimate the severity of the aortic insufficiency. Furthermore, the effect of the aortic insufficiency was appraised by comparison of the values of coronary blood flow found in a group of normal dogs with the values observed in the group of dogs with aortic insufficiency. Hence, no strict control values for coronary blood flow were available. The observations made on patients with aortic insufficiency are sparse and variable in their conclusions. Bing and his coworkers (12) reported coronary blood flow and cardiac oxygen consumption to be definitely increased in one case of aortic insufficiency as compared to a group of normal persons. Regan, Talmers, Christensen, Wada, and Hellems (13) reported that in three patients with severe aortic insufficiency the coronary flow was 91,100 and $107 \mathrm{ml}$. per 100 grams of left ventricle per minute, and the oxygen consumption averaged $12.7 \mathrm{ml}$. per 100 grams of left ventricle per minute. In two patients with aortic insufficiency and angina pectoris the coronary blood flow was 66 and 68 $\mathrm{ml}$., and the oxygen consumption $8 \mathrm{ml}$. per 100 grams of left ventricle per minute. These data were compared with data obtained on a group of 8 normal persons in whom the coronary blood flow was 103 plus or minus $20 \mathrm{ml}$. per 100 grams of left ventricle per minute, and the oxygen consumption was 10.5 plus or minus $2.6 \mathrm{ml}$. per 100 grams of left ventricle per minute. Such data are difficult to assess and hazardous to interpret 
because of the small number of observations, the lack of adequate control data and the impossibility of ever ruling out the presence of complicating factors such as diseases of the coronary ostia and/ or arteries.

In conclusion, it would seem that an acute aortic insufficiency severe enough to lower markedly the mean arterial blood pressure, as well as the aortic diastolic pressure, resulted in an increase in cardiac oxygen consumption and coronary blood flow. This increase in coronary flow must be due to a decrease in the resistance of the coronary bed, since the coronary flow rose despite a marked drop of the aortic pressure. This decrease in the resistance of the coronary bed was probably induced by the increase in the work of the left ventricle (14). Whether the increase in coronary flow was sufficient to meet the demands made upon the left ventricle by the aortic insufficiency, and thereby prevent myocardial ischemia, cannot be determined from these experiments.

\section{SUMMARY AND CONCLUSIONS}

In the anesthetized dog acute aortic insufficiency, sufficient to lower markedly the mean arterial blood pressure and the aortic diastolic pressure, resulted regularly in an increase in coronary sinus blood flow and myocardial oxygen consumption.

\section{REFERENCES}

1. Blumgart, H. L. Diseases of the coronary arteries. Angina pectoris in A Textbook of Medicine, R. L. Cecil and R. F. Loeb, Eds. Philadelphia, W. B. Saunders Co., 1955, p. 1321.

2. Harrison, T. R. Principles of Internal Medicine, 2nd ed. New York, Blakiston Co., 1954, p. 32.

3. Green, H. D. The coronary blood flow in aortic stenosis, in aortic insufficiency and in arteriovenous fistula. Amer. J. Physiol. 1936, 115, 94.
4. Green, H. D., and Gregg, D. E. Changes in the coronary circulation following increased aortic pressure, augmented cardiac output, ischemia and valve lesions. Amer. J. Physiol. 1940, 130, 126.

5. Foltz, E. L., Wendel, H., and West, J. W. Effects of aortic insufficiency on coronary blood flow and cardiac oxygen consumption (abstract). Fed. Proc. 1953, 12, 44.

6. Wégria, R., Frank, C. W., Misrahy, G. A., Sioussat, R. S., McCormack, G. H., Jr., and Sommer, L. S. A new technic for the continuous recording of the cardiac output. Proc. Soc. exp. Biol. (N. Y.) 1950, 74, 551.

7. Shipley, R. E., and Wilson, C. An improved recording rotameter. Proc. Soc. exp. Biol. (N. Y.) 1951, 78, 724.

8. Gregg, D. E., and Shipley, R. E. Studies of the venous drainage of the heart. Amer. J. Physiol. 1947, $151,13$.

9. Wégria, R., Frank, C. W., Wang, H. H., Blumenthal, M. R., Kornfeld, P., and Seely, R. D. Effect of elevation of right ventricular pressure on coronary circulation. Fed. Proc. 1954, 13, 162.

10. Wiggers, C. J., and Maltby, A. B. Further observations on experimental aortic insufficiency. IV. Hemodynamic factors determining the characteristic changes in aortic and ventricular pressure pulses. Amer. J. Physiol. 1931, 97, 689.

11. Van Slyke, D. D., and Neill, J. M. The determination of gases in blood and other solutions by vacuum extraction and manometric measurement. J. biol. Chem. 1924, 61, 523.

12. Bing, R. J., Hammond, M. M., Handelsman, J. C., Powers, S. R., Spencer, F. C., Eckenhoff, J. E., Goodale, W. T., Hafkenschiel, J. H., and Kety, S. S. Measurement of coronary blood flow, oxygen consumption and efficiency of the left ventricle in man. Amer. Heart J. 1949, 38, 1.

13. Regan, T. J., Talmers, F. N., Christensen, R. C., Wada, T., and Hellems, H. K. Coronary blood flow and myocardial metabolism in aortic insufficiency. Circulation 1956, 14, 987.

14. Anrep, G. V., and Segall, H. N. The regulation of coronary circulation. Heart 1926, 13, 239. 